\title{
Artificial Insemination for Species in Danger
}

\section{Robert T. Francoeur}

Artificial insemination is widely used throughout the world in the breeding of domestic animals. Why should not this technique be adapted and applied to build up populations of rare and endangered species?

In 1776 Abbé Lazzaro Spalanzani, an embryologist-priest, artificially inseminated the eggs of 165 female frogs in his rectory, and four years later successfully inseminated a canine bitch. In 1799 Dr. Home, a British physician, artificially inseminated the first woman. In the 1890s English dog breeders tried their hands at artificial insemination. In 1899 E. I. Ivanoff was asked by the chief of the Royal Russian Stud Farm to explore the uses of artificial insemination to improve the Russian horse stock. Ivanoff went on to inseminate cattle, sheep and birds successfully, in each case improving on the natural conception rate. The first co-operative organised to take advantage of the efficiency of artificial insemination came in 1936 in Denmark. Two years later the Holstein breeders in New Jersey formed the first American cooperative for artificial insemination.

Since the late 1950s we have been able to freeze semen in straws and store it for ten years, if not indefinitely, without genetic deterioration. The breeding of domesticated animals with frozen semen and artificial insemination is now an impressive and profitable business. (In 1971 sperm banks for frozen human semen were opened as commercial ventures in several American cities.) One recent farm census in the USA indicates that 59 million cows, 47 million ewes, one million sows, 125,000 mares and 56,000 goats were artificially inseminated in a single year; in some countries 99 per cent of all calves born are the product of artificial insemination, and in the United States each year over four million turkey hens are artificially inseminated. But this technique has found little use among the 4000 species of mammals other than the domesticated ungulates, and even less with other animals.

Considering the long-standing concern of many ecologists, zoo managers, environmentalists and naturalists around the world, I find it incredible and disturbing that so little attention has been given to the possible uses and advantages of artificial insemination in the attempt to save endangered animal species from extinction. The National Academy of Medicine, in a literature search of its computer memory bank (MEDLARS) undertaken at my request, turned up only three experiments with the artificial insemination of non-human primates between January 1, 1970 and October 1, 1971, and revealed less than a dozen

Dr Francoeur is associate professor of experimental embryology at Fairleigh Dickinson University, Madison, New Jersey, USA. 
reports of artificial insemination being attempted with semidomesticated or wild hoofed animals: the water buffalo, alpacas and some African antelopes. Nothing could be found on the artificial insemination of birds, reptiles or fish. There has been an occasional experiment in academia, as for instance, Dr. Cade's insemination of a red-tailed hawk at Cornell University, and probably some work at various game preserves and primate centres, but these do not turn up in the MEDLARS bibliography.

At the same time, natural environments and reserves everywhere are being invaded and destroyed by man, driving more and more wild populations to the verge of extinction. In captivity, many of these animals refuse to breed unless they have benefited from watching mating behaviour during an infancy in the wild, and/or unless a close mimic of their natural environment, food, light, temperature, space and population size can be knowingly provided by their captors. But with our limited knowledge of these animals and their behaviour and requirements in the wild, the task of developing a quasi-natural captive environment is an almost impossible challenge, a groping-in-the-dark effort rarely rewarded with success. Natural reserves are disappearing, breeding in captivity is often limited to adults imported from the wild, nations are placing embargos on the capture and export of many species, and we are left with dwindling zoo populations scattered haphazardly among hundreds of zoos and game reserves around the world.

My impressions from general reading and from a discussion of this problem with John Perry, assistant director of the National Zoological Park, Washington DC, and secretary of the Wild Animal Propagation Trust, confirm my suspicion that with many endangered species we do not have either the time or the populations to continue the tedious groping search for simulated natural breeding facilities. Radical as it may sound to some naturalists, the best hope lies in the suggestion I put forward over a year ago in Utopian Motherhood, ${ }^{*}$ and more recently in an article for Catalyst for Environmental Quality, for a consortium, a research team composed of zoo managers, experts in animal behaviour and husbandry, reproductive physiologists and experimental embryologists. Each would bring his or her own expertise to a carefully planned project to experiment with artificially inseminated captive stock. Frozen semen, drawn from a cooperative breeding pool, would be supplied by the participating institutions. Breeding females would be committed by the participating zoos and maintained wherever the best facilities could be found. Finances would be handled jointly.

A dozen scientists and naturalists, I feel, could handle this project, drawing where need be on the experience and expertise of scientists around the world. We have the manpower, the basic knowledge and the raw material to launch this venture. The question is whether the right people can be convinced of the advantages of using artificial insemination to preserve some endangered species.

The obstacles are not insurmountable if the expertise of experimental embryologists, animal behaviour specialists and reproductive

*Doubleday, 1970; Allen \& Unwin, 1971. 
physiologists can be called on. Methods will have to be developed to determine, control and perhaps even induce oestrus in females, and to collect and freeze the semen, and equipment and techniques for the insemination will have to be found. Zoos and reserves will have to be convinced that it is in their best interests to contribute to the sperm banks and loan their females to the project, and finance sought.

The first attempts at artificial insemination of exotics might be made either on species which though not rare are closely related to rare forms, or on species which are closely related to domesticated forms where artificial insemination has been extensively proven. In both cases, species could be chosen which can be handled with a minimum of risk arising from physical restraint or drug immobilisation, a risk which varies and is often unknown in the rarer species. A good subject for an early experiment could be the pair of bongos in the Milwaukee Zoo where the male is too lame to service the female and there is little chance of obtaining another male. The knowledge gleaned from many successful cases of artificial insemination of domesticated hoofed animals could be applied to these bongo with a minimum of risk. In another area, if experiments with the commoner marmosets proved successful, artificial insemination might be tried with the golden lion marmoset.

Another technique in experimental embryology might also be worthwhile considering: artificial inovulation or embryo transplantation to a surrogate mother of another closely related species after test-tube fertilisation of eggs from a superovulated rare female. Embryo transplants with bovine and sheep embryos are about 75 per cent successful. At present there are only 44 Indian rhinoceroses in 25 zoos and only eight births have been reported since 1964, five of them at Basle. Is it too far-fetched to suggest inducing superovulation of a single female with hormones, collecting the eggs non-surgically, fertilising them in vitro and then implanting the resultant embryos in the wombs of more common black rhinoceroses which have been synchronised in their oestrous cycle. The same technique might be used with the more common marmosets serving as surrogate mothers for the rare golden lion marmoset, or the common American bison assisting as a prenatal wet nurse for the European bison.

The techniques are available and have been proven with extensive experience among domesticated and human animals. The question is whether those concerned with preserving our endangered species are interested in exploring some new avenues.

\section{Save the Robin in Malta}

A Save the Robin publicity campaign in Malta last year was 'a marvellous success', according to Police Inspector Joe Attard, who is President of the Malta Ornithological Society. 'Everyone now knows that the robin is a protected bird'. The problem is trapping for sale. Eight hundred posters supplied by the Malta Bird Reserves Overseas Committee were displayed widely and distributed to all the boys' schools, with the result that when Inspector Attard (in civilian clothes) visited the Sunday market in Valletta he found none for sale. 